\title{
Inducible bronchus-associated lymphoid tissue (iBALT) in patients with pulmonary complications of rheumatoid arthritis
}

\author{
Javier Rangel-Moreno, ${ }^{1}$ Louise Hartson, ${ }^{1}$ Carmen Navarro, ${ }^{2}$ Miguel Gaxiola, ${ }^{2}$ \\ Moises Selman, ${ }^{2}$ and Troy D. Randall ${ }^{1}$ \\ ${ }^{1}$ Trudeau Institute, Saranac Lake, New York, USA. ${ }^{2}$ Instituto Nacional de Enfermedades Respiratorias, Mexico City, Mexico.
}

\begin{abstract}
Bronchus-associated lymphoid tissue (BALT) was originally described as a mucosal lymphoid organ in the lungs of some species. However, while the lungs of naive mice and humans typically lack BALT, pulmonary infection in mice leads to the development of inducible BALT (iBALT), which is located in peribronchial, perivascular, and interstitial areas throughout the lung. Here we investigated whether iBALT forms in patients with a variety of interstitial lung diseases. We show that while iBALT can be found in the lungs of patients suffering from multiple diseases, well-developed iBALT is most prevalent in patients with pulmonary complications of RA and Sjögren syndrome. In these patients, iBALT consisted of numerous B cell follicles containing germinal centers and follicular dendritic cells. A loosely defined $T$ cell area surrounded the $B$ cell follicles while lymphatics and high endothelial venules were found at the B cell/T cell interface. Increased expression of lymphoid-organizing chemokines, such as CXCL13 and CCL21, as well as molecules involved in the immunopathology of RA, such as B cell-activating factor of the TNF family (BAFF), ICOS ligand, and lymphotoxin, correlated with more well-developed iBALT. Finally, the presence of iBALT correlated with tissue damage in the lungs of RA patients, suggesting that iBALT participates in local RA pathogenesis.
\end{abstract}

\section{Introduction}

Bronchus-associated lymphoid tissue (BALT) was originally described as a submucosal lymphoid organ, similar to Peyer patches, found along the bifurcations of the upper bronchi directly beneath the epithelium and generally lying between an artery and a bronchus (1). Although some species appear to develop BALT independently of antigenic stimulation (2), most normal mice and humans have little evidence of BALT (3). However, pulmonary infection or inflammation in mice leads to the development of lymphoid follicles that are not restricted to the upper airways and are termed inducible BALT (iBALT) (4). Similar areas are occasionally found in humans with pulmonary diseases (5-10). However, there is little information about what type of pulmonary disease leads to the development of iBALT or the cellular and molecular mechanisms that control the formation of this pulmonary structure.

The homeostatic chemokines CXCL13, CCL19, and CCL21 are important for the organization of secondary lymphoid tissues and are required for efficient adaptive immune responses (11-13). CXCL13 is mainly produced by reticular cells, such as follicular dendritic cells (FDCs) (11), and attracts CXCR5 ${ }^{+}$cells to the B cell follicle $(14,15)$. In contrast, CCL21 and CCL19 are produced by stromal cells (16), high endothelial venules (HEVs) (12), and

Nonstandard abbreviations used: BAFF, B cell-activating factor of the TNF family; BAL, bronchoalveolar lavage; BALT, bronchus-associated lymphoid tissue(s); CCP, cyclic citrullinated peptide; FDC, follicular DC; HEV, high endothelial venule; HP, hypersensitivity pneumonitis; iBALT, inducible BALT; ICOS-L, ICOS ligand: IPF, idiopathic pulmonary fibrosis; LT, lymphotoxin; NSIP, nonspecific interstitial pneumonia; PADI-2, peptidyl arginine deiminase-2; PCNA, proliferating cell nuclear antigen; PNAd, peripheral lymph node addressin; SS, Sjögren syndrome; UIP, usual interstitial pneumonia.

Conflict of interest: The authors have declared that no conflict of interest exists. Citation for this article: J. Clin. Invest. 116:3183-3194 (2006). doi:10.1172/JCI28756
DCs and attract CCR7 ${ }^{+} \mathrm{T}$ cells as well as activated CCR7 ${ }^{+} \mathrm{DCs}$ and $\mathrm{B}$ cells to the $\mathrm{T}$ cell zone $(12,16)$. The coordinated activities of these chemokines maintain the compartmentalized structure of lymphoid tissues and make encounters between lymphocytes and activated, antigen-bearing APCs more likely $(11,12)$, ultimately leading to more efficient immune responses $(16,17)$. Homeostatic chemokines are also important for the development of lymphoid organs during embryogenesis (18-21) and are expressed in ectopic lymphoid structures in murine and human diseases characterized by chronic inflammation (22-37). In each case, the formation of ectopic lymphoid follicles is thought to be triggered by chronic inflammation caused by autoimmunity or infection (reviewed in refs. 38, 39).

In this study, we determined whether a variety of interstitial lung diseases of known and unknown etiology could lead to the formation of iBALT. Surprisingly, we found that despite severe pulmonary pathology in many cases, iBALT was preferentially formed in the lungs of patients with pulmonary complications of RA and Sjögren syndrome (SS). Well-developed iBALT in RA lungs consisted of B cell follicles containing central FDC networks and zones of active B cell proliferation with a germinal center-like structure. T cells surrounded the follicles and sometimes formed interfollicular zones. We also observed expression of peripheral lymph node addressin (PNAd) and the lymphatic marker M2A on endothelial cells around the $\mathrm{B}$ cell follicles on the borders of the $\mathrm{B}$ and $\mathrm{T}$ cell areas. The increased expression of a wide variety of chemokines (CXCL13, CXCL9, CXCL14, CCL11, and CCL19) as well as several cytokines and costimulatory molecules (B cell-activating factor of the TNF family [BAFF], ICOS ligand [ICOS-L], lymphotoxin $\alpha[\mathrm{LT} \alpha], \mathrm{LT} \beta$, and IL-13) and the transcription factor BCL-6 correlated with an increased number and structural complexity of iBALT areas in the lung. Finally, iBALT formation 
Table 1

Demographic and clinical features of patients with interstitial lung disease

\begin{tabular}{|c|c|c|c|c|}
\hline & $\mathrm{RA}(n=9)$ & SS $(n=3)$ & $\operatorname{IPF}(n=7)$ & $\mathrm{HP}(n=6)$ \\
\hline Age & $47 \pm 14.1$ & $60.3 \pm 6.4$ & $59 \pm 9.1$ & $47 \pm 9.3$ \\
\hline $\operatorname{Sex}(F / M)$ & $9 / 0$ & $2 / 1$ & $0 / 7$ & $6 / 0$ \\
\hline $\begin{array}{l}\text { Duration of lung symptoms } \\
\text { before diagnosis (mo) }\end{array}$ & $22.9 \pm 24.6$ & $30.3 \pm 21.1$ & $30.9 \pm 20.6$ & $7.3 \pm 6.5$ \\
\hline $\begin{array}{l}\text { Duration of rheumatic symptoms } \\
\text { before diagnosis (mo) }\end{array}$ & $54.2 \pm 120.5$ & $6.0 \pm 2.0$ & - & - \\
\hline FVC predicted (\%) & $57.6 \pm 17.4$ & $75.0 \pm 25.4$ & $58.1 \pm 8.6$ & $56.8 \pm 13.8$ \\
\hline $\mathrm{FEV}_{1}$ predicted $(\%)$ & $59.9 \pm 20.7$ & $82.0 \pm 26.9$ & $68.9 \pm 8.5$ & $59.5 \pm 14.7$ \\
\hline $\mathrm{FEV}_{1} / \mathrm{FVC}$ & $83.5 \pm 15.9$ & $89.7 \pm 5.7$ & $92.1 \pm 7.6$ & $90.9 \pm 4.05$ \\
\hline $\mathrm{PaO}_{2}$ & $50.1 \pm 11.8$ & $58.1 \pm 6.4$ & $49.6 \pm 7.4$ & $57.3 \pm 2.8$ \\
\hline Sat $\mathrm{O}_{2}$ & $84.8 \pm 76.1$ & $90.6 \pm 1.8$ & $87.8 \pm 5$ & $90 \pm 5.1$ \\
\hline BAL Macrophages (\%) & $74.5 \pm 19$ & $65.0 \pm 13.5$ & $80.7 \pm 7.4$ & $34.7 \pm 23.9$ \\
\hline Lymphocytes (\%) & $21.2 \pm 19.7$ & $33.0 \pm 14.2$ & $12.9 \pm 7.6$ & $64 \pm 24.4$ \\
\hline Neutrophils (\%) & $0.3 \pm 0.5$ & $0.3 \pm 1.3$ & $3.3 \pm 3.5$ & $0.67 \pm 1.2$ \\
\hline Eosinophils (\%) & $4.0 \pm 7.0$ & $0.6 \pm 1.2$ & $2.7 \pm 2$ & $0.5 \pm 0.5$ \\
\hline
\end{tabular}

FVC, forced vital capacity; $\mathrm{FEV}_{1}$, forced expiratory volume in 1 second; $\mathrm{PaO}_{2}$, arterial pressure of oxygen (normal values at Mexico City altitude, $67 \pm 3 \mathrm{mmHg}$ ); Sat $\mathrm{O}_{2}$, oxygen saturation.
We next confirmed the presence of iBALT using immunofluorescence. We found that lung biopsies from RA patients contained clearly organized iBALT, with CD21+ FDCs (Figure 2, $\mathrm{A}-\mathrm{F}), \mathrm{CD} 20^{+} \mathrm{B}$ cell areas with proliferating cell nuclear antigen-positive $\left(\mathrm{PCNA}^{+}\right.$) germinal center B cells (Figure 2, G-L), $\mathrm{CD} 68^{+}$macrophage-like cells both inside and outside the follicles (Figure 2, M-R), and T cells surrounding the follicles and in the interfollicular areas (Figure 2, S-X). Again, biopsies from RA patients exhibited iBALT ranging from the small, poorly organized follicles shown in Figure 2, A and G, to the large, well-organized follicles with polarized germinal centers in Figure 2, F and L. In contrast, most of the biopsies from patients with other types of pulmonary disease did not have FDCs (summarized in was also associated with local collagen deposition, citrullination of proteins in the lung, and local production of antibodies against citrullinated proteins. Thus, the formation of BALT is observed in pulmonary complications of RA and is associated with the development of local pathology.

\section{Results}

$i B A L T$ is found in some patients with interstitial lung disease. In order to determine whether chronic inflammation in the lung results in the formation of iBALT, we examined lung biopsies from patients suffering from a variety of chronic pulmonary diseases. Patients were grouped according to disease, and the demographic and clinical features of patients in major groups - those with RA, SS, idiopathic pulmonary fibrosis (IPF), and hypersensitivity pneumonitis (HP) - are listed in Table 1. All patients in the RA group were tested for SS by serology and clinical evaluation and were deemed negative. Regardless of group, all patients exhibited clinical, radiological, and functional evidence of interstitial lung disease, with variable degrees of dyspnea, decreased lung capacities, and hypoxemia at rest that worsened during exercise (40).

We first examined sections of healthy lung (Figure 1A) as well as sections from patients with IPF/usual interstitial pneumonia (UIP) (Figure 1, B and C), HP (Figure 1D), silicotuberculosis (Figure 1E), bronchoalveolar carcinoma (Figure 1F), SS (Figure 1G), and RA (Figure 1, H-L). Slides were stained with $\mathrm{H} \& \mathrm{E}$, and we looked for clusters of lymphocytes that were suggestive of lymphoid follicles. As expected, healthy lung did not show any appreciable accumulations of lymphocytes or inflammatory cells (Figure 1A). In contrast, sections of lungs from patients with interstitial lung disease showed a wide variety of phenotypes, ranging from scattered lymphocytes (Figure 1C) to small lymphoid aggregates (Figure 1, B, E, and G) and even numerous, large accumulations of lymphocytes that have the appearance of highly organized lymphoid follicles (Figure 1, F, $\mathrm{J}$, and L). Although the majority of samples did have at least some small lymphoid aggregates, samples from patients with RA and SS consistently had more and larger lymphoid areas. However, even in the samples from RA patients, lymphoid aggregates exhibited a range of sizes and degrees of organization (Figure 1, G-L).
Table 2). In these cases, only small clusters of disorganized B cells or $\mathrm{T}$ cells were detected. In fact, lymphoid aggregates that could be classified as iBALT were observed in only 2 of 10 patients with idiopathic interstitial pneumonias, 2 of 6 patients with HP, 0 of 4 patients with chronic infectious disease, and 1 of 4 patients with cancer. In contrast, 8 of 9 patients with pulmonary disease associated with RA and 3 of 3 patients with pulmonary disease associated with SS exhibited iBALT in their lungs (Table 2). These findings support the idea that iBALT is not strictly induced by pulmonary inflammation and that some diseases, such as RA, are more effective at eliciting organized lymphoid areas in the lung than others. Interestingly, lungs from patients with IPF, a disease characterized by epithelial cell injury/activation, fibroblastic foci formation, and exaggerated accumulation of extracellular matrices (41), did not display iBALT (0 of 7 patients) (Table 2).

Areas of well-organized $i B A L T$ contain PNAd $\mathrm{d}^{+} \mathrm{HEVs}$ and $\mathrm{M}_{2} \mathrm{~A}^{+}$lymphatic vessels. In order to establish whether areas of BBALT were simply locally organized accumulations of lymphocytes in areas of inflammation or were accessible to recirculating lymphocytes, we examined the expression of PNAd in samples containing iBALT. As shown in Figure 3, PNAd ${ }^{+}$HEVs could often be observed in biopsies that contained well-developed iBALT. These HEVs were typically observed near the edge of the follicles at the B cell/T cell interface (Figure 3, B, C, and F). Although PNAd staining was usually observed in cells that had characteristics of endothelial cells (Figure 3, A, B, and F), it was also observed in cells in a similar location, but with a less obvious endothelial morphology (Figure $3, \mathrm{C}$ and $\mathrm{E}$ ). In contrast, $\mathrm{PNAd}^{+} \mathrm{HEVs}$ were more difficult to find in less-organized inflammatory areas and were impossible to find in normal lung biopsies (not shown). We also observed endothelial cells that expressed the lymphatic marker M2A immediately surrounding the B cell follicles in areas of well-developed iBALT (Figure 3, B-E). In addition, expression of this marker was occasionally observed in a reticular pattern inside large B cell follicles that contained germinal centers (Figure 3, C and F). However, in less well-developed areas of iBALT, the lymphatic marker M2A was often expressed by isolated cells or short linear clusters of cells, which may represent lymphatic vessel precursors (not 

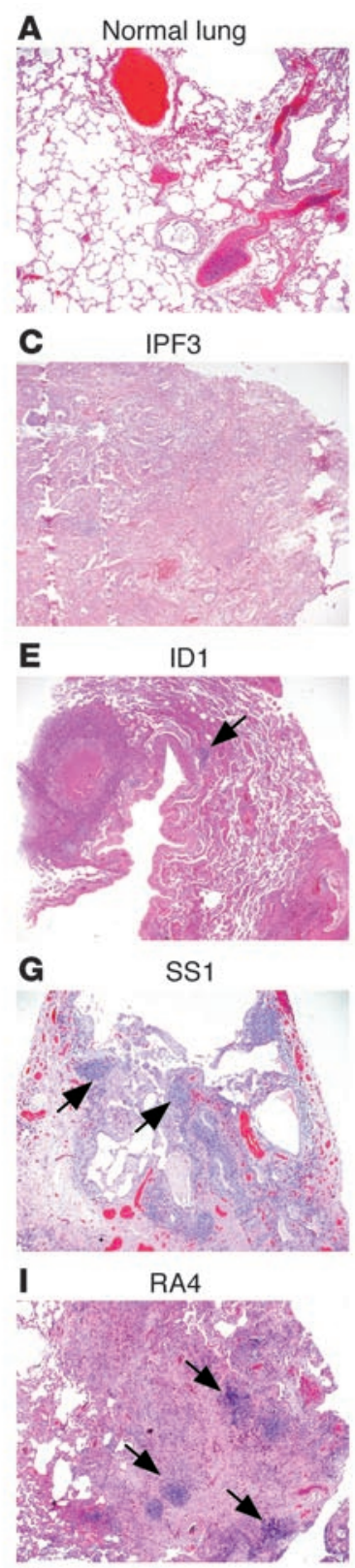

K RA6

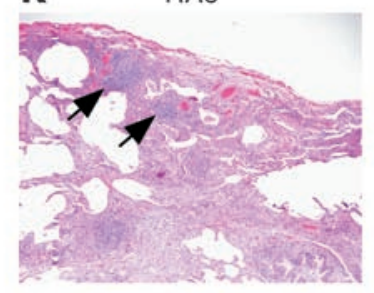

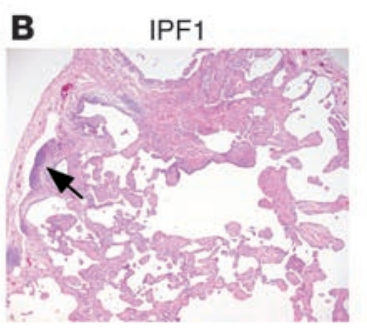
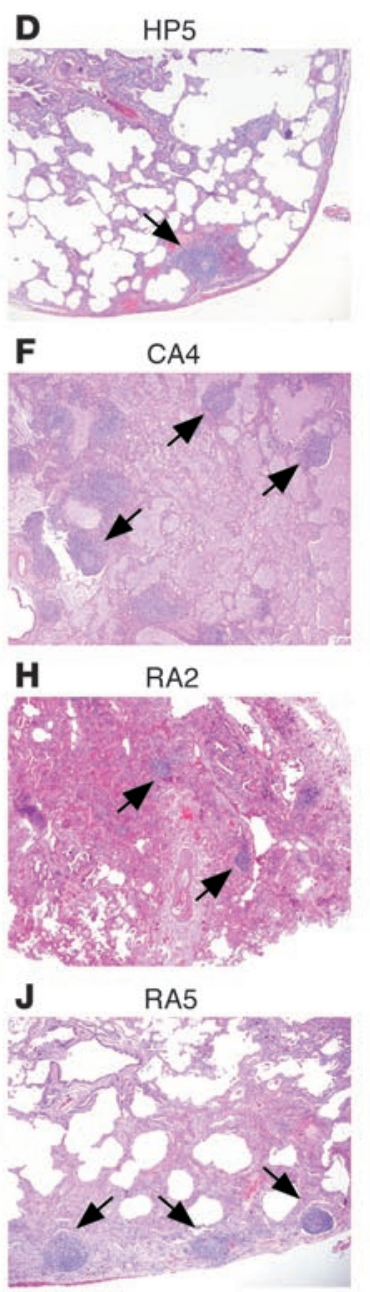

$\mathbf{L}$

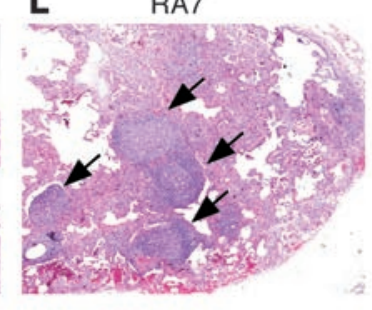

shown). Moreover, in normal lung, only a few small lymphatic vessels were detected by immunofluorescence (not shown). Thus, it appears that $\mathrm{PNAd}^{+} \mathrm{HEV}$ s and $\mathrm{M}_{2} \mathrm{~A}^{+}$lymphatic vessels are located at the interface between $\mathrm{B}$ cell follicles and $\mathrm{T}$ cell areas, where they are positioned to facilitate entry and exit of immune cells to and from areas of iBALT.

Homeostatic chemokines and $L T$ are expressed in areas of $i B A L T$ formation. We next tested whether homeostatic chemokines were

\section{Figure 1}

Lymphoid aggregates can be observed in sections of human lungs from patients with different interstitial lung diseases. Sections of formalin-fixed, paraffin-embedded lung biopsies from patients with various interstitial lung diseases were stained with H\&E. Sample numbers are indicated for parts $\mathbf{A}-\mathbf{L}$, and the corresponding clinical diagnoses and summaries of histological findings are presented in Table 2. Original magnification, $\times 20$. Arrows in all panels point to examples of lymphoid follicles.

expressed at sites of iBALT formation. As shown in Figure 4A, CCL21 was most easily observed on endothelial cells surrounding the B cell follicle in an area similar to where HEVs and lymphatic vessels were observed. At larger magnification, CCL21 was clearly observed on endothelial-like cells that had a concentric distribution in structures that looked like blood vessels (Figure 4B). Although we did not find colocalization of CCL21 and PNAd (not shown), we did observe colocalization of CCL21 and the lymphatic marker M2A (Figure 4C). Finally, we observed limited expression of CCL21 in a reticular pattern in the $\mathrm{T}$ cell areas outside the follicles (Figure 4D), consistent with expression by stromal cells or dendritic cells. We also examined the expression of CXCL13, which is normally expressed in B cell follicles. As shown in Figure 4, E-H, we found that CXCL13 was expressed in the B cell follicle in a pattern characteristic of FDCs. However, we also found strong CXCL13 labeling on fibroblast-like cells, fibrils, and blood vessels outside of the B cell follicle (Figure 4, E and F). We occasionally observed CXCL13-producing CD $68^{+}$cells in the B cell follicle (Figure 4G), which may be germinal center dendritic cells, as previously reported (42). These results demonstrate that the homeostatic chemokines are expressed in a spatially separated fashion in which CXCL13 appears to be involved in the organization of the B cell follicle and CCL21 appears to coordinate the traffic of cells to and from areas of iBALT.

The expression of homeostatic chemokines is controlled by LT signaling in secondary lymphoid organs $(43,44)$. LT is also crucial for the expression of the enzymes that regulate PNAd expression and the development of HEVs $(45,46)$. Therefore, we determined whether LT $\alpha$-producing cells could be found in areas of iBALT. As shown in Figure 4, I-L, LT $\alpha$-producing cells were located on the edge of B cell follicles in T cell areas of iBALT adjacent to where PNAd $^{+}$HEVs were found (Figure 3 ). The location of these cells and the high level of cytoplasmic staining for LT suggested that they may be activated T cells, which are high producers of this cytokine (43). Interestingly, the number of $\mathrm{LT}^{+}$cells surrounding the follicular areas increased as iBALT increased in size and organization (Figure 4, I and J). Thus, the expression of LT $\alpha$ in the T cell area correlates with the formation and expansion of iBALT.

Expression of chemokines and cytokines in iBALT. To get a better idea of how various molecules are expressed in tissues that exhibit progressive degrees of iBALT formation, we extracted RNA from tissue samples that were frozen at the time of biopsy and used quantitative PCR to measure the expression of chemokines and cytokines that are involved in lymphoid organogenesis and lung pathology. As shown in Figure 5A, the expression of the chemokines CXCL13, CXCL9, CCL1, CXCL14, and CCL18 was dramatically increased in samples from RA patients relative to their expression in normal lung. Similarly, the expression of mRNA for CCL11, CCL2, CCL19, CXCL10, and CCL21 was modestly increased in samples from RA patients (Figure 5B). In each of these cases, increased expression 


\section{Table 2}

Characteristics of iBALT in patients with interstitial lung disease

\begin{tabular}{|c|c|c|c|c|c|c|c|}
\hline No. & Patient & Diagnosis & $\mathrm{FDCs}^{\mathrm{A}}$ & B cells & T cells & No. follicles & No. GCs \\
\hline \multicolumn{8}{|l|}{$\mathrm{RA}$} \\
\hline RA1 & $191-88$ & NSIP pattern and FB & + & + & + & 15 (small) & NF \\
\hline RA2 & $150-00$ & NSIP pattern with UIP-like lesions and FB & ++ & ++ & + & 40 (medium) & 6 \\
\hline RA3 & $192-04$ & UIP pattern & NF & ++ & + & 57 (small) & 20 \\
\hline RA4 & $\underline{314-01}$ & UIP pattern and FB & ++ & +++ & ++ & 58 (medium) & 18 \\
\hline RA5 & $208-00$ & NSIP pattern and FB & ++ & +++ & ++ & 50 (medium) & 20 \\
\hline RA6 & $\underline{179-01}$ & NSIP pattern with UIP-like lesions & ++ & ++ & ++ & 80 (medium) & 28 \\
\hline RA7 & $\overline{181-03}$ & NSIP pattern with UIP-like lesions and FB & +++ & +++ & +++ & 96 (large) & 80 \\
\hline RA8 & $\underline{547-99}$ & NSIP, UIP lesions, and FB & + & + & + & 14 (medium) & 2 \\
\hline RA9 & $\overline{72-00}$ & NSIP and FB & + & + & + & 17 (medium) & 2 \\
\hline \multicolumn{8}{|l|}{ SS } \\
\hline SS1 & $\underline{147-05}$ & Primary SS, NSIP pattern, FB, RA & ++ & ++ & + & 40 (medium) & 10 \\
\hline SS2 & $\underline{731-02}$ & RA, secondary SS, NSIP, & + & + & + & 20 (medium) & 2 \\
\hline SS3 & $\underline{296-05}$ & Primary SS, RA, NSIP, UIP & + & + & + & 32 (medium) & 5 \\
\hline \multicolumn{8}{|c|}{ Idiopathic interstitial pneumonias } \\
\hline IPF1 & $653-03$ & IPF/UIP & NF & + & + & 2 (small) & ND \\
\hline IPF2 & $134-04$ & IPF/UIP & NF & + & + & 11 (small) & ND \\
\hline IPF3 & $402-97$ & IPF/UIP & NF & + & + & 16 (small) & NF \\
\hline IPF4 & $494-01$ & IPF/UIP & NF & + & + & 15 (small) & 4 \\
\hline IPF5 & $180-01$ & IPF/UIP & NF & ++ & + & 27 (small) & 4 \\
\hline IPF6 & $483-98$ & IPF/UIP & NF & ++ & + & 37 (small) & 1 \\
\hline IPF7 & $63-02$ & IPF/UIP & NF & ++ & + & 40 (small) & 5 \\
\hline IIP1 & 396-05 & DIP & + & ++ & + & 45 (small) & 20 \\
\hline IIP2 & $2466-4-1-C$ & DIP & NF & ++ & + & 50 (small) & 20 \\
\hline IIP3 & $\underline{534-05}$ & NSIP & + & ++ & + & 80 (small) & 11 \\
\hline \multicolumn{8}{|c|}{ Interstitial lung disease of known etiology } \\
\hline HP1 & $166-03$ & $\mathrm{HP}$ & NF & ++ & + & 20 (small) & ND \\
\hline HP2 & $\underline{179-03}$ & HP & + & ++ & + & 25 (small) & 6 \\
\hline HP3 & $\overline{397-04}$ & HP & NF & ++ & + & 27 (small) & 4 \\
\hline HP4 & $84-00$ & HP & NF & ++ & + & 35 (small) & 4 \\
\hline HP5 & $401-03$ & $\mathrm{HP}$ & NF & ++ & + & 40 (small) & ND \\
\hline HP6 & $\underline{575-03}$ & HP & + & ++ & + & 40 (medium) & 10 \\
\hline \multicolumn{8}{|c|}{ Infectious diseases } \\
\hline ID1 & $104-87$ & Silicotuberculosis & NF & + & + & NF & NF \\
\hline ID2 & $130-04$ & Histoplasmosis & NF & + & + & NF & NF \\
\hline ID3 & $A-4501-20$ & Tuberculosis & NF & + & + & 4 (small) & NF \\
\hline ID4 & EP-14-00 & Tuberculosis & NF & + & + & 12 (small) & NF \\
\hline \multicolumn{8}{|c|}{ Lung cancer } \\
\hline $\mathrm{CA} 1$ & EP-7-00 & Adenocarcinoma & NF & + & + & NF & NF \\
\hline $\mathrm{CA} 2$ & Zero/one & Adenocarcinoma & NF & + & + & 10 (small) & NF \\
\hline CA3 & $221-1-86$ & Squamous cell carcinoma & NF & + & + & 14 (small) & NF \\
\hline CA4 & $258-04$ & Bronchoalveolar carcinoma & + & +++ & ++ & 80 (large) & 50 \\
\hline
\end{tabular}

Diagnosis, tissue collection, and initial histopathological analysis were performed at the Instituto Nacional de Enfermedades Respiratorias. Thin sections of paraffin-embedded tissues were also analyzed by immunofluorescence at the Trudeau Institute. Tissues were probed with anti-CD21 (FDCs), anti-CD20 (B cells), anti-CD3 (T cells), and anti-PCNA (proliferating cells). Patients were grouped according to diagnosis: RA (RA1-RA9), SS (SS1-SS3), idiopathic interstitial pneumonia (IPF1-IPF7 and IIP1-IIP3), HP (HP1-HP6), infectious diseases (ID1-ID4), and cancer (CA1-CA4). Patient numbers that are underlined indicate those who had iBALT. ARelative frequency of FDC clusters; ${ }^{B}$ Number of germinal centers per slide. FB, follicular bronchiolitis; NF, not found; ND, not determined; DIP, desquamative interstitial pneumonia.

of these chemokines correlated with increased number, size, and organization of iBALT in the corresponding slides (Figures 1 and $2)$. In contrast, the expression of other chemokines, including CCL17, CXCL2, and CXCL12, either did not substantially increase relative to that in normal controls or, in the case of CXCL8, actually went down (Figure 5C). Thus, increases in the expression of only a subset of chemokines correlate with iBALT formation.
We also examined the expression of cytokines that are known to be involved in lymphoid organogenesis. As shown in Figure 5D, the expression of LT $\alpha$ and, more strikingly, the expression of LT $\beta$ were increased in lung samples from RA patients. Similar increases were observed in the expression of IL-13 and the transcription factor BCL-6 (Figure 5D), which is highly expressed in germinal center $B$ cells $(47,48)$. In contrast, although TNF and IFN- $\gamma$ were increased 

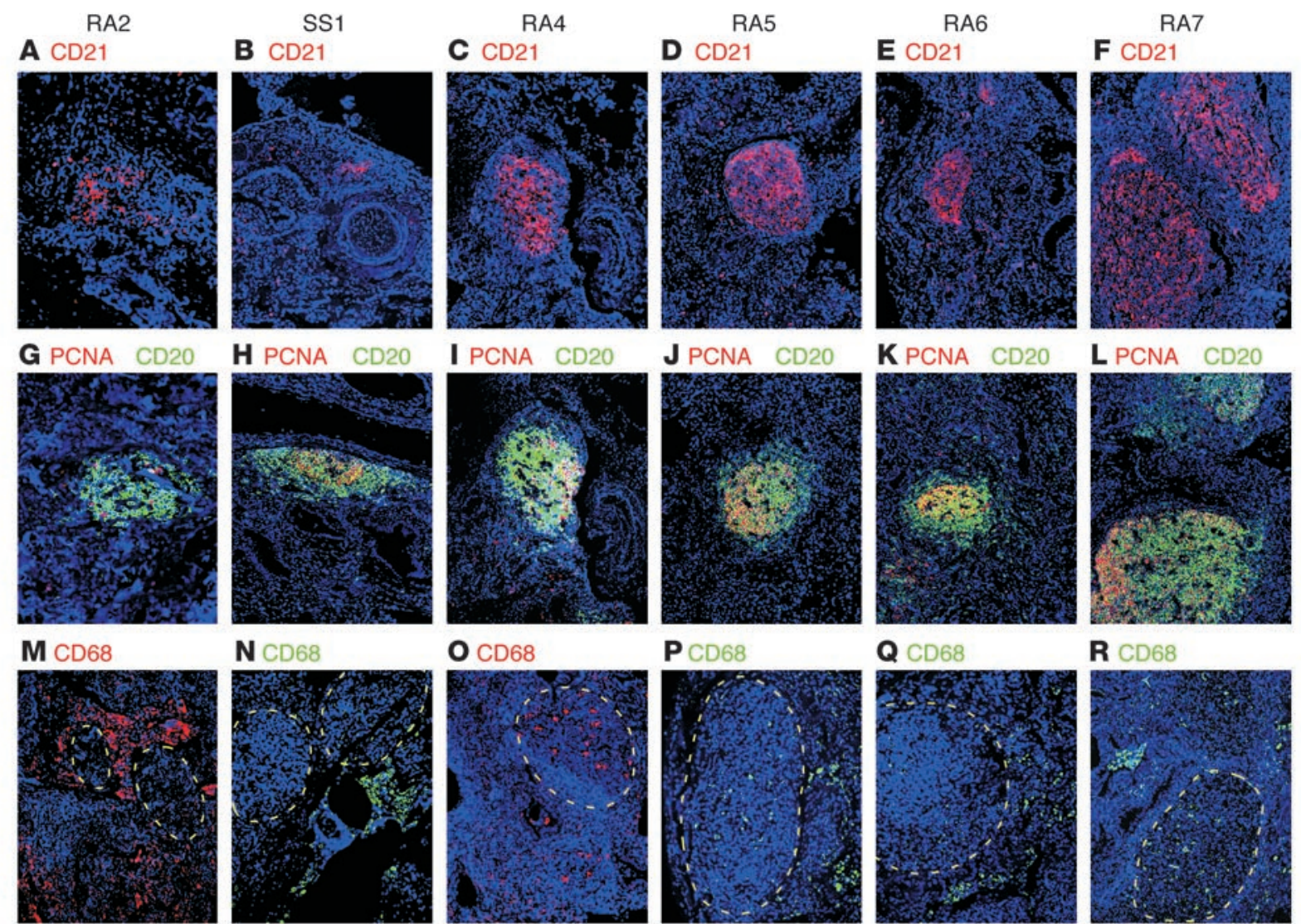

R $\mathrm{CD} 68$
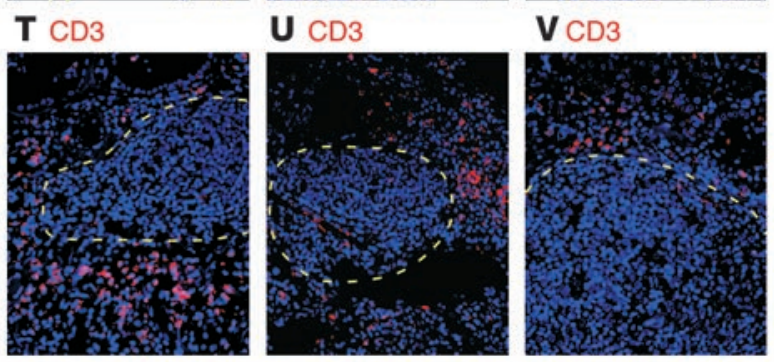

\section{$\mathbf{W} \mathrm{CD} 3$}

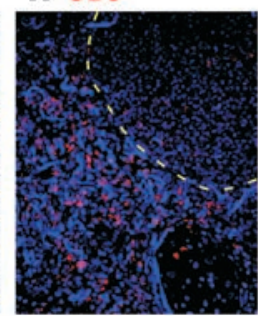

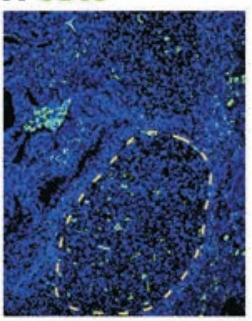

$\mathbf{X} \mathrm{CD} 3$

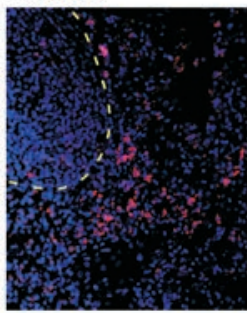

Figure 2

Cellular organization of iBALT in the lungs of patients with RA. Sections of formalin-fixed, paraffin-embedded lung biopsies from patients with RA were analyzed by immunofluorescence using antibodies specific to CD21 (A-F), CD20 and PCNA (G-L), CD68 (M-R), and CD3 (S-X). All sections were counterstained with DAPI (blue). The B cell follicles are outlined with dashed yellow lines in $\mathbf{M}-\mathbf{X}$. Original magnification, $\times 100$.

in some samples relative to their expression in normal controls (Figure 5D), these increases did not correlate with increased size and complexity of iBALT. Thus, the level of iBALT organization correlates with the expression of molecules involved in lymphoid organogenesis and with the expression of some molecules involved in Th2-driven pathology.

We also analyzed the expression of several cytokines, costimulatory molecules, and enzymes that are involved in the pathogenesis of RA. As shown in Figure 6, the enzyme peptidyl arginine deiminase-2 (PADI-2), which is involved in the citrullination of proteins (49), is highly expressed in biopsies containing iBALT relative to its expression in normal lung. Similarly, the costimulatory molecule ICOS and ICOS-L are highly expressed in the lungs of RA patients as is the B cell stimulatory cytokine BAFF (Figure 6). Thus, molecules associated with lymphoid organogenesis and RA pathogenesis are highly expressed in areas of iBALT. To determine whether iBALT supported local immune responses to autoantigens, we next looked for plasma cells specific for rheumatoid factor or citrullinated proteins in areas of iBALT. As shown in Figure 7 , we found scattered cells that bound biotinylated human IgG (Figure 7A) or citrullinated proteins (Figure 7B) surrounding the follicles of iBALT. These cells exhibited cytoplasmic staining and had plasma cell morphology (Figure 7, C and D). These data suggest that some iBALT follicles support the differentiation of B cells specific for autoantigens.

We also determined whether autoantibodies could be found in the serum or bronchoalveolar lavage (BAL) fluid from patients with RA. Although rheumatoid factor could easily be detected in the serum of RA patients (Figure 7E), we did not find detectable levels of rheumatoid factor in the BAL fluid (not shown). In con- 

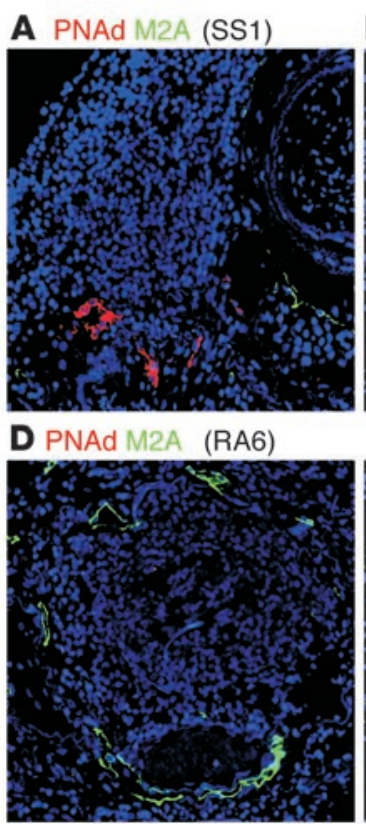

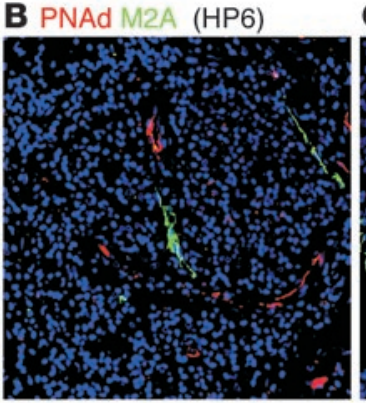

E PNAd M2A (RA5)

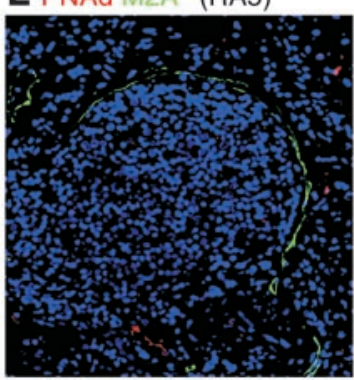

C PNAd M2A (IIP1)

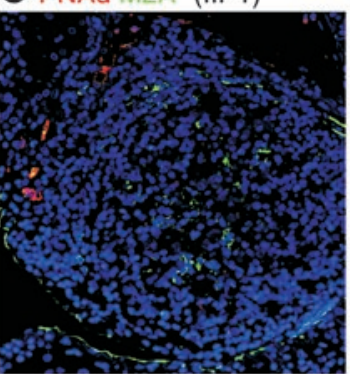

F PNAd M2A (RA7)

\section{Figure 3}

Vascular endothelial cells expressing markers of lymphatic vessels and HEVs are found surrounding the B cell follicles. Sections of formalin-fixed, paraffin-embedded lung biopsies from patients with RA ( $\mathbf{A}$ and $\mathbf{D}-\mathbf{F}), \mathrm{HP}(\mathbf{B})$, and desquamative interstitial pneumonia (C) were analyzed by immunofluorescence using antibodies specific for lymphatic endothelium (M2A) and HEVs (PNAd). All sections were counterstained with DAPI (blue). Original magnification, $\times 200$. trast, anti-cyclic citrullinated peptide (anti-CCP) antibodies were observed in both serum and BAL fluid of RA patients (Figure 7F). Furthermore, the levels of anti-CCP antibodies were increased in patients that had more well-developed iBALT. These data suggest that anti-CCP antibodies are produced locally in the lung and contribute to pulmonary pathology.

The formation of $i B A L T$ is associated with tissue damage in the lung. We next looked for the deposition of collagen, the development of fibrosis, and the presence of citrullinated proteins in the lung as measures of pathology in areas surrounding iBALT in the lungs of RA patients. Staining with Masson trichrome revealed dense areas of collagen deposition surrounding the follicles, blood vessels, and airways in lungs of RA patients that exhibited highly organized iBALT (Figure 8A). We

\section{Figure 4}

The chemokines CXCL13 and CCL21 as well as the cytokine $L T \alpha$ are expressed in areas of iBALT. Sections of formalin-fixed, paraffin-embedded lung biopsies from patients with RA (A, D, E, H-L), HP ( $\mathbf{B}$ and $\mathbf{C})$, and desquamative interstitial pneumonia ( $\mathbf{F}$ and $\mathbf{G}$ ) were analyzed by immunofluorescence using antibodies specific to CCL21 and CD3 (A, B, and D), CCL21 and M2A (C), CXCL13 and CD68 $(\mathrm{E}-\mathrm{H})$, and $\mathrm{LT} \alpha(\mathrm{I}-\mathrm{L})$. All sections were counterstained with DAPI (blue). B cell follicles are outlined with dashed yellow lines in panels I-L. Original magnification, $\times 100$ (A, E, F, and I-L); ×200 (B, G, and H); $\times 400$ (C and D).
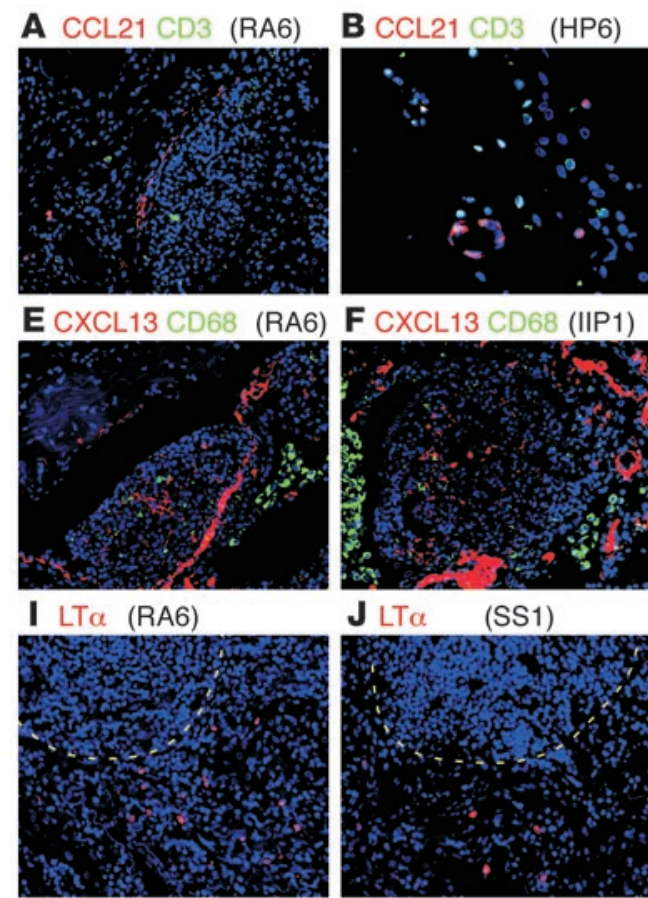

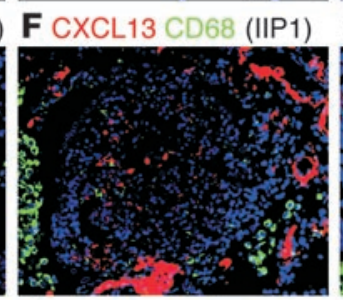

$\mathbf{J} \mathrm{LT}_{\alpha} \quad(\mathrm{SS} 1)$

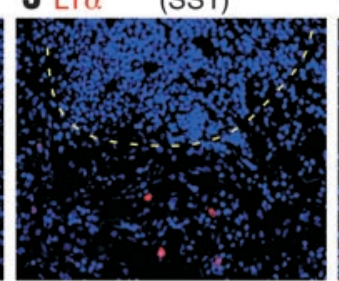

also examined the expression of $\alpha$-SMA, which is a classic marker of myofibroblasts with increased proliferative and fibrogenic activity and is generally linked to an exaggerated local inflammatory/ fibrotic response. In lung sections from patients with RA, increased numbers of cells expressing $\alpha$-SMA were found in areas adjacent to airways and blood vessels and, in some cases, even surrounding the follicles (Figure 8B). These areas were often close to germinal centers, as detected by staining with PCNA (Figure 8B). Furthermore, extensive areas of citrullinated proteins were observed in and around iBALT follicles (Figure 8C). Thus, the presence of BBALT in the lungs of RA patients appears to correlate with local pathology.

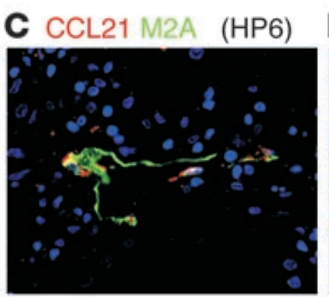

G CXCL13 CD68 (IIP1)

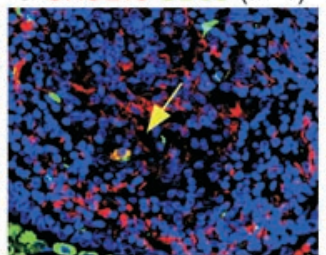

K LT $\alpha$ (RA5)

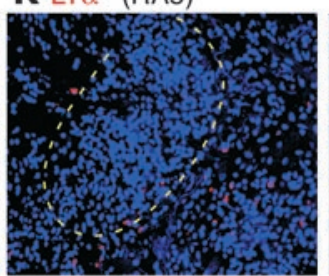

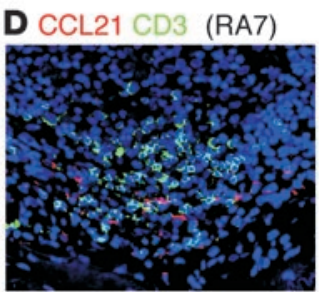

HCXCL13 CD68 (RA7)

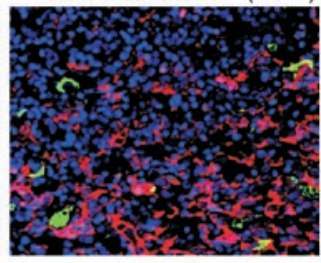

L LT $\alpha$ (RA7)

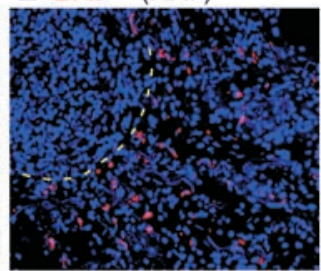



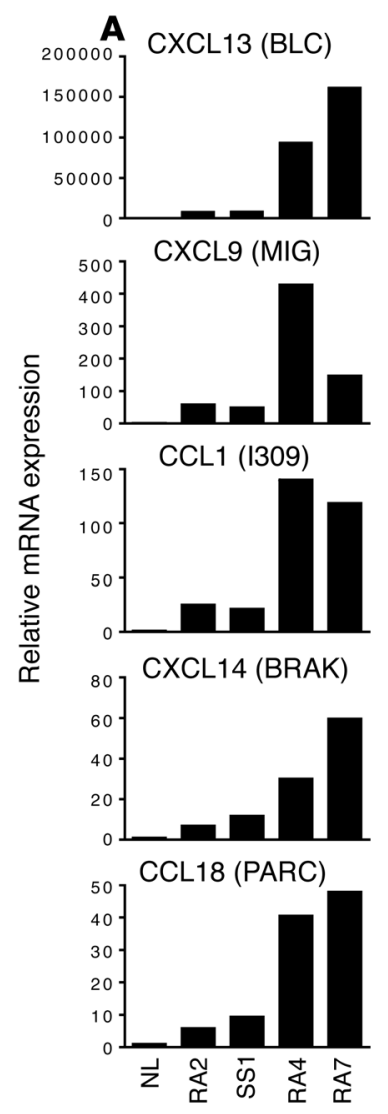
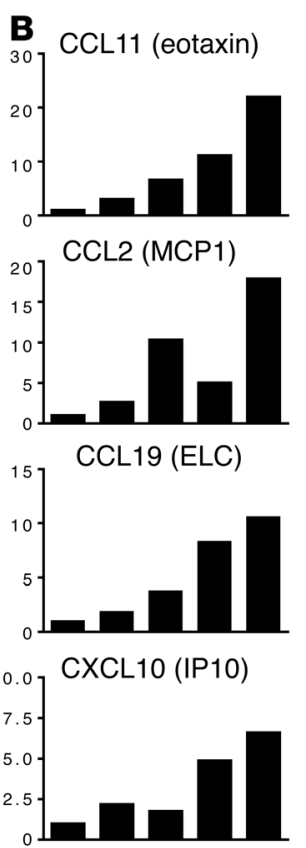

CCL21 (SLC)

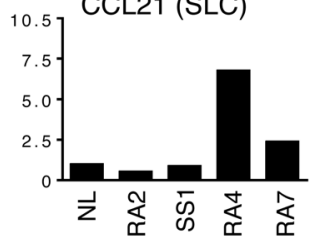

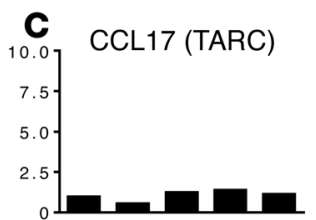

CXCL2 (GRO)
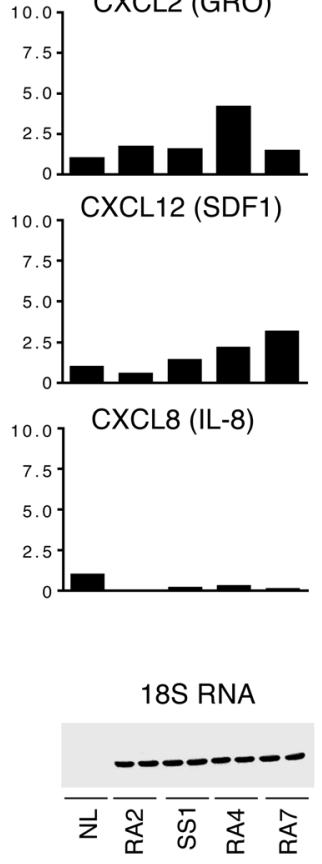
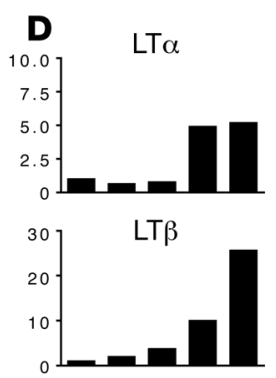

TNF- $\alpha$
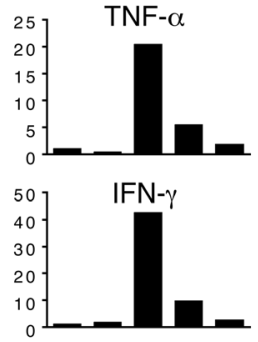

$\mathrm{IL}-13$
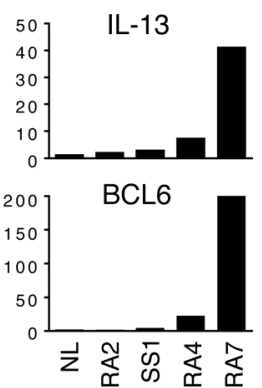

\section{Figure 5}

Expression of genes that correlate with lymphoid tissue organization in lung biopsies that contain iBALT. DNA-free RNA was extracted from normal lung (NL) or lung biopsies from patients who had pulmonary diseases associated with RA. The 4 samples selected exhibited a range of phenotypes from those with low levels of iBALT (RA2 and SS1), higher levels of iBALT (RA4), and the highest levels of iBALT (RA7). Extracted mRNA was reverse transcribed and used in a quantitative PCR array to determine relative mRNA expression patterns. The mRNA levels of each gene in each sample were first normalized to the expression of 18S RNA in that sample and then normalized to the expression of that gene in normal lung. The expression of selected chemokine mRNAs showed strong increases (A), moderate increases (B), or no increases (C) relative to mRNA expression in normal lung. The expression of selected cytokine mRNAs was also compared with that in normal lung (D). The levels of 18S RNA in the 4 patient samples were independently analyzed (in duplicate) by semiquantitative PCR and shown to be similar in all samples (bottom panel of $\mathbf{C}$ ).

\section{Discussion}

Our data show that iBALT is present in the lungs of patients with a wide variety of interstitial lung diseases. However, BBALT is most prevalent in patients with pulmonary manifestations of autoimmune diseases, such as RA and SS. In these patients, iBALT is associated with the expression of chemokines and cytokines that support lymphoid tissue development and organization. The presence of well-organized iBALT is also associated with the local expression of cytokines, costimulatory molecules, and enzymes that are involved in the pathology of RA. Consistent with a possible role in local pathology, patients with well-developed iBALT exhibited higher levels of anti-CCP antibodies in BAL fluid. Thus, iBALT appears to play a role in pulmonary manifestations of RA.

The original observations of BALT by Bienenstock (50) described a novel mucosal lymphoid tissue underlying a dome epithelium along the large airways. In contrast, the lymphoid follicles described here are found in both the upper and lower lungs and rarely have the typical dome structure of mucosal lymphoid tissues. Instead, they have the appearance of ectopic lymphoid follicles like those in rheumatoid joints (35). Therefore, we have termed these areas inducible BALT or $i B A L T$ in order to distinguish them from classic BALT structures, which are true mucosal lymphoid tissues.

Classic BALT that is observed in some species is constitutively present in the absence of antigenic stimulation (2, 51-53), suggesting that its formation is developmentally regulated. However, pigs raised in a pathogen-free environment and humans who died from nonrespiratory causes generally lack detectable BALT (2). Moreover, in human fetal and infant lungs, organized BALT is often found in cases of amnionitis or intrauterine pneumonia but is found in only $10 \%$ of fetuses without any evident sign of infection and is poorly organized in these cases $(10,54)$. Moreover, iBALT is not detectable in the lungs of naive C57BL/ 6 mice but does develop after influenza infection (4). Together, these data suggest that BALT is induced primarily after antigen encounter. However, it is not clear how the follicles of iBALT gain access to antigen without a dome epithelium that contains $\mathrm{M}$ cells for transporting antigen. Although we do observe lymphatic vessels surrounding the B cell follicles of iBALT, we do not 


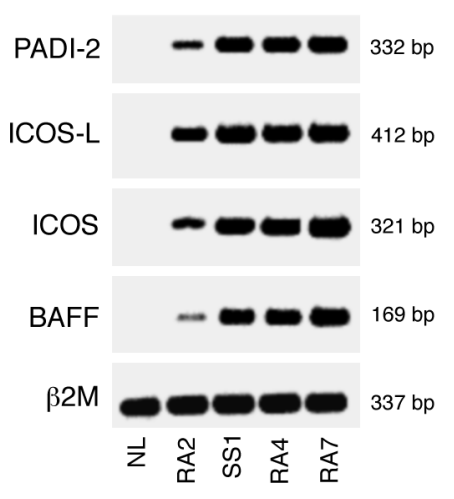

Figure 6

Expression of genes that correlate with RA pathology in lung biopsies that contain iBALT. DNA-free RNA was extracted from normal lung or lung biopsies from patients who had pulmonary diseases associated with RA. Extracted mRNA was reverse transcribed and used in semiquantitative PCR reactions to determine relative mRNA expression patterns. Samples were analyzed for expression of PADI-2, ICOS-L, ICOS, and BAFF. The expression of $\beta 2 \mathrm{M}$ was used as a control for mRNA quality and loading. PCR products were resolved on agarose gels, and the bands represent the only products observed. No bands were detected from RNA samples that were not reverse transcribed.

know whether they are afferent or efferent lymphatics or both. Afferent lymphatics could be supplying antigen and APCs from distal parts of the lung. However, if only efferent lymphatics are present, then it seems that only autoantigens located directly in iBALT would be available to stimulate lymphocytes. This may explain why iBALT is so extensive in RA patients.

If continuous exposure to antigen is the driving force behind iBALT formation, it is not altogether surprising that silica par- ticles or cancers lacking recognizable tumor antigens are insufficient to induce iBALT formation. In contrast, patients with RA and SS are continuously exposed to autoantigens while patients with HP are frequently exposed to particular environmental antigens, consistent with the extensive iBALT in these patients. However, exposure to antigen cannot be the only factor involved in the development of iBALT since cigarette smoke and adverse environmental exposure are also linked to iBALT induction $(3,55$, 56). In addition, one might predict that the presence of live organisms such as Mycobacterium tuberculosis and Histoplasma capsulatum would be associated with iBALT formation, as they are clearly a source of antigen. Thus, the specific type of immune response, the type of cells that are activated, and the cytokines that are produced are likely to play key roles in the development of iBALT beyond simple exposure to antigen.

The formation of ectopic lymphoid tissue at other sites correlates with the local expression of homeostatic chemokines (27, $30,34,36,37,42,57)$. In fact, the induction of CXCL13 expression is one of the strongest correlates for the development of ectopic lymphoid follicles in rheumatoid joints. Furthermore, the overexpression of CXCL13 at ectopic sites, such as the pancreas, is sufficient to drive the development of ectopic lymphoid follicles with B and T cell areas, FDCs, and HEVs (58). Although CXCL13 is constitutively expressed in conventional lymphoid tissues, we know from previous studies that it is inducibly expressed in the lung after influenza infection (4). Therefore, it is not surprising that CXCL13 is the most strongly induced mRNA that we examined in the biopsies of lung tissue containing iBALT and that its level of expression correlates with the extent of iBALT formation. These data suggest that the induced expression of CXCL13 is important for the development of iBALT. However, it is unclear exactly how CXCL13 is involved. During embryogenesis, CXCL13 plays a key role in the recruit-

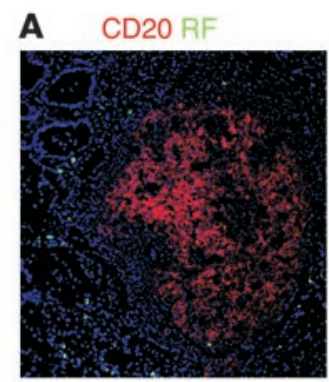

$$
\text { E }
$$

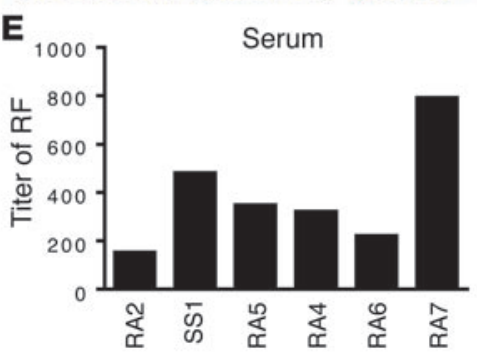

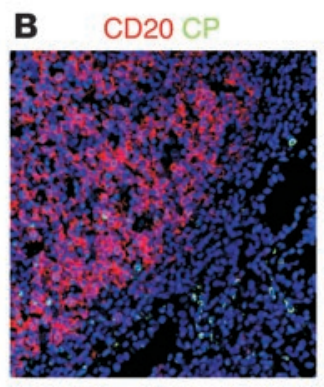

$\mathbf{F}$

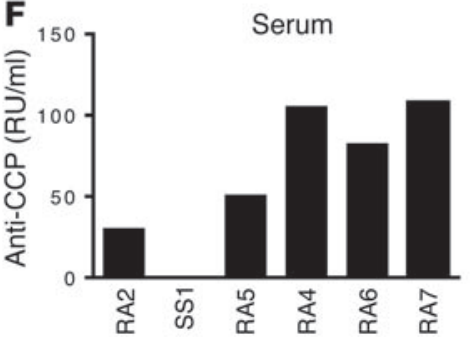

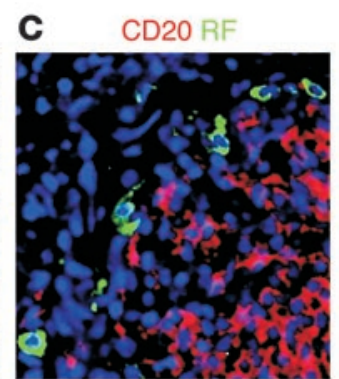

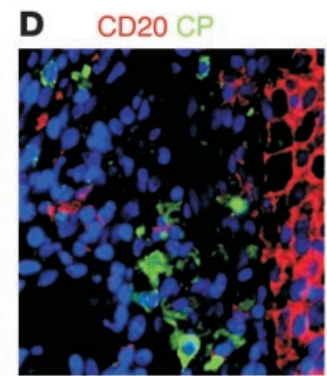

BAL

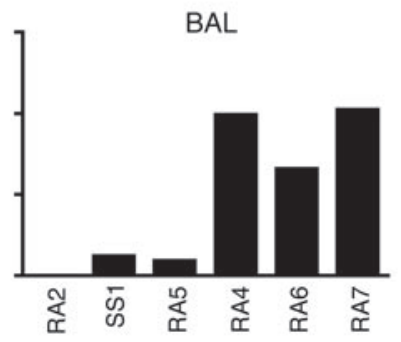

Figure 7

Local production of autoantibodies in the lungs of RA patients with iBALT. Sections were stained with biotinylated human IgG (A and C) to detect plasma cells producing rheumatoid factor (RF) or with citrullinated fibrinogen (B and $\mathbf{D}$ ) to detect plasma cells producing antibodies against citrullinated proteins (CP). Sections were counterstained with anti-CD20 to detect B cell follicles (A-D). Original magnification, $\times 100$. Titers of rheumatoid factor in serum were determined by ELISA (E). Relative units of anti-CCP antibodies in serum and BAL fluid were determined by ELISA (F). RU, relative units. 

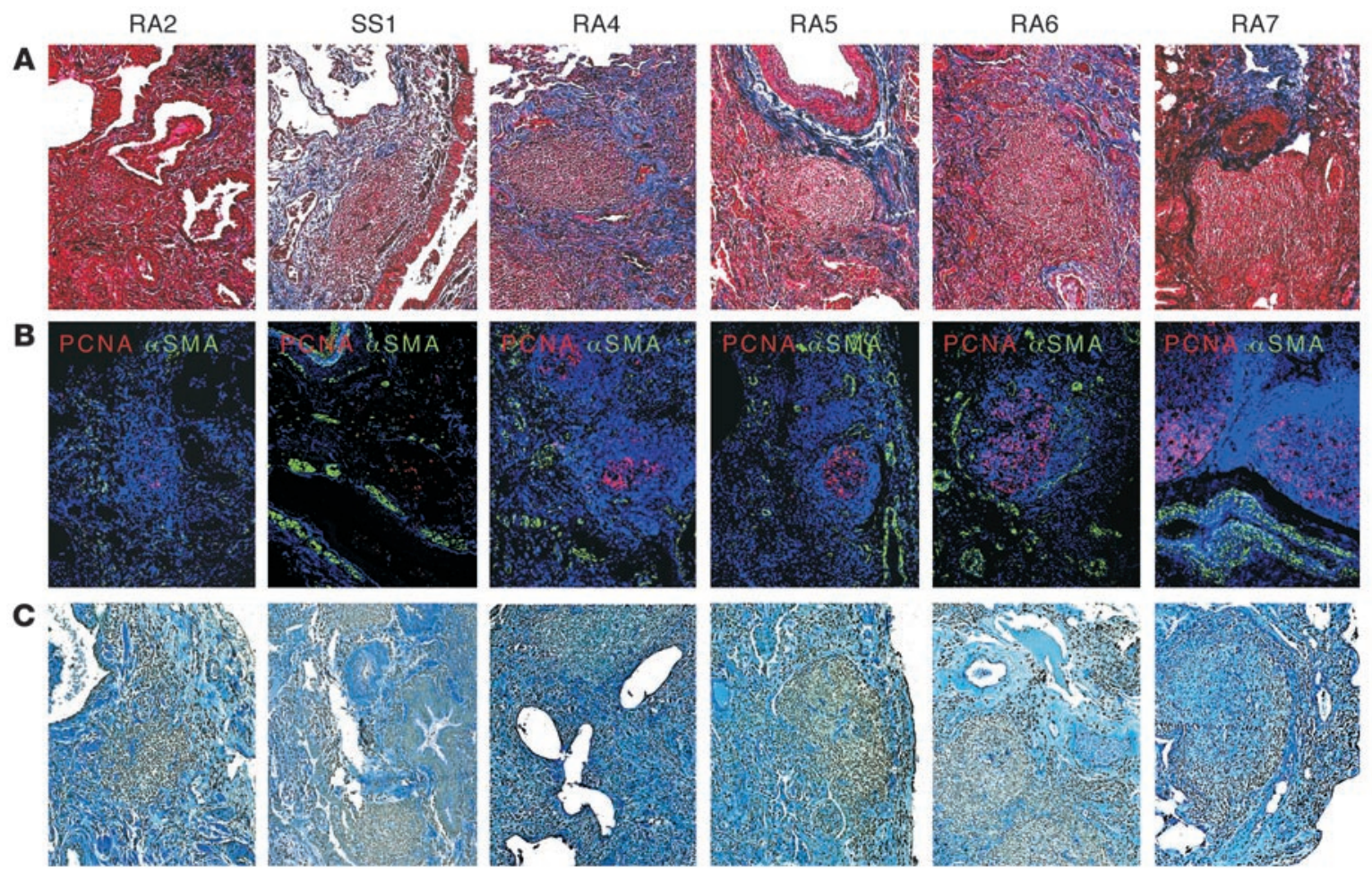

Figure 8

Local pathology correlates with iBALT formation in lung biopsies from RA patients. Sections of formalin-fixed, paraffin-embedded lung biopsies from patients with RA were stained with Masson trichrome to detect fibroblasts and collagen deposition (A) and stained with antibodies against $\alpha$-SMA (green) and PCNA (red) (B). Samples in B were also counterstained with DAPI (blue). Sections were treated to modify citrullinated proteins, which were detected by immunohistochemistry (C). Original magnification, $\times 100$ (normal lung in B, $\times 200$ ).

ment of LTi cells, which initiate the formation and organization of lymphoid organs, such as LNs and Peyer patches (21). Thus, the induced expression of CXCL13 may recruit similar types of cells to the lung, which initiate the formation of iBALT. On the other hand, CXCL13 may simply serve to recruit B cells and organize them into follicles. Since they express LT $\alpha \beta$ heterotrimers on their surfaces (59), B cells may be sufficient to initiate the formation of iBALT. Similar events probably take place in rheumatoid joints that develop ectopic lymphoid follicles. However, the relationship between the structures in the joints of RA patients and those in the lungs remains unclear.

Based on its role in the organization of other lymphoid tissues (44) and the dramatically increased expression of LT $\beta$ that we observed in areas of iBALT, it is likely that LT is also involved in iBALT formation. Consistent with this, increasing numbers of LT $\alpha$-producing cells were observed in the T cell zone as the number and size of iBALT areas increased (Figure 4). These LT $\alpha^{+}$cells are likely to be activated $\mathrm{T}$ cells, which can produce large amounts of this cytokine. However, we did not observe LT $\alpha$ expression on $\mathrm{B}$ cells in follicles, possibly due to the low level of LT expression on B cells (44) and the limited sensitivity of immunofluorescence. LT is also important for the differentiation of HEVs and for the expression of PNAd $(43,45,46,60)$. In the samples of human lungs studied here, LT $\alpha$-producing cells were located around the $B$ cell follicles in areas where we found vessels that expressed PNAd. Thus, it is possible that interactions between LT $\alpha$-expressing cells and TNF-R1- or LT $\beta$ R-expressing endothelial cells could trigger the development of HEVs and the expression of PNAd. Therefore, LT $\alpha$ probably plays a role in the expression of homeostatic chemokines, the maintenance of B cell follicles, and the differentiation of PNAd-expressing HEVs in areas of iBALT.

A final issue is whether immune responses in iBALT are beneficial or detrimental to pulmonary function. In the examples shown here, iBALT is clearly associated with pathology, including local fibrosis, collagen deposition, citrullination of proteins, and production of cytokines and chemokines such as IL-13 and CCL11, which are associated with the pathology of asthma (61). The presence of $\alpha-\mathrm{SMA}^{+}$cells, fibroblasts, and collagen in close proximity to germinal centers suggests that iBALT is playing an active role in the induction of local immune responses that are responsible for local tissue damage. Moreover, the presence of plasma cells specific for citrullinated proteins and the high levels of anti-CCP antibodies found in the BAL fluid suggest that autoantibodies are produced locally in the lung - possibly after the expansion of autoreactive B cells in the germinal centers of iBALT. Thus, iBALT may exacerbate local pathology in response to autoantigens. However, the presence of BBALT also appears to play a beneficial role in mice infected with influenza and promotes functional local $\mathrm{T}$ and $\mathrm{B}$ cell responses that clear virus without triggering systemic pathology (4). Therefore, it is important to understand the mechanisms that control iBALT formation and function and use this information to develop ways to intervene in pulmonary pathology and to enhance respiratory immunity to pathogens 


\section{Methods}

Tissue samples and patient diagnosis. Archival samples of diagnostic lung biopsies from 36 patients were used in this study. Two biopsies were obtained from each patient, and slides from each biopsy were examined. Biopsies and serum samples were obtained for diagnosis purposes upon informed consent of the subjects. The protocol for collecting biopsies and serum samples was approved by the Ethics Committee of the Instituto Nacional de Enfermedades Respiratorias. Diagnosis of IPF was confirmed by tissue findings of UIP (62). Pathological diagnosis of idiopathic nonspecific interstitial pneumonia (NSIP) and desquamative interstitial pneumonia were established by their typical morphologic features as described elsewhere (62). Morphological evaluation of HP showed diffuse interstitial inflammation, primarily around bronchioles. The inflammatory infiltrate consisted predominantly of mononuclear cells, mainly lymphocytes, although clusters of multinucleated giant cells or small and loosely arranged granulomas were also observed (63). Diagnosis of RA and SS was done according to criteria recommended by the American College of Rheumatology $(64,65)$. Lung morphologic findings were classified as described (66) and included NSIP pattern, UIP pattern, and follicular bronchiolitis. Patients with infectious lung diseases also presented with interstitial lung disease of unknown etiology, and the precise diagnosis was confirmed upon biopsy. Tissue samples were taken by open lung biopsy, usually 1 week after hospital admission. None of the patients had been treated with corticosteroids or immunosuppressive drugs at the time of biopsy.

ELISA. Rheumatoid factor was measured in serum and BAL by ELISA. Antibodies against CCP were detected in serum and BAL using a commercial ELISA kit (Immunoscan RA; EURO-DIAGNOSTICA) according to the instructions of the manufacturer. Results were reported as relative units/ $\mathrm{ml}$ and were considered positive above 5 relative units $/ \mathrm{ml}$.

Histochemical and immunofluorescent staining. Sections were stained with $\mathrm{H} \& \mathrm{E}$ for standard histology and with Masson trichrome to detect collagen deposition. For immunofluorescent staining, slides were incubated at $60^{\circ} \mathrm{C}$ overnight to melt the paraffin and then hydrated in xilol, alcohol, and water. For antigen retrieval, slides were immersed in $0.01 \mathrm{M}$ citrate, $\mathrm{pH}$ 6, and heated at $96^{\circ} \mathrm{C}$ for 30 minutes. For CXCL13 staining, antigen retrieval required adding $500 \mu \mathrm{g} / \mathrm{ml}$ proteinase $\mathrm{K}$ (Roche Diagnostics) in $50 \mathrm{mM}$ Tris, $1 \mathrm{mM}$ EDTA, $\mathrm{pH}$ 8.0, for 5 minutes at $37^{\circ} \mathrm{C}$. Nonspecific binding was blocked with $5 \%$ normal donkey serum and $2 \mu \mathrm{g} / \mathrm{ml} \mathrm{Fc} \mathrm{block}$ for 30 minutes. Endogenous biotin was blocked with a sequential avidinbiotin incubation step (Sigma-Aldrich). Primary antibodies were incubated overnight at room temperature. Labeled secondary antibodies were incubated for 3 hours at room temperature. Finally, slides were incubated with streptavidin conjugated to either Alexa Fluor 594 or Alexa Fluor 488 and counterstained with ProLong Gold antifade with DAPI from Invitrogen. All sections were viewed with a Zeiss Axioplan 2 microscope. Images were recorded with a Zeiss AxioCam HR digital camera.

Antibodies. Unlabeled antibodies included rabbit anti-CD3 $\varepsilon$ and antiCD21 (2G9) from Lab Vision Corp.; anti-CD20 (L26) and anti-CD68 (PG-M1) from Dako; goat anti-PCNA from Santa Cruz Biotechnology Inc.; anti-TNF- $\beta$ (5802.21), goat anti-CXCL13, goat anti-CCL21, and anti$\alpha$-SMA (1A4) from R\&D Systems; anti-PNAd (MECA 79) from BD Biosciences; and anti-M2A (D2-40) from Vector Laboratories. Secondary antibodies included biotinylated $\mathrm{F}\left(\mathrm{ab}^{\prime}\right)_{2}$ donkey anti-mouse IgG and biotinylated $\mathrm{F}\left(\mathrm{ab}^{\prime}\right)_{2}$ donkey anti-rabbit IgG from Jackson ImmunoResearch Laborato- ries Inc.; Alexa Fluor 594-labeled donkey anti-goat IgG from Molecular Probes; and Texas Red-labeled donkey anti-rat IgM from Sigma-Aldrich.

Detection of plasma cells secreting antibodies against $R F$ and citrullinated proteins. Citrullinated fibrinogen was generated as described (67). Briefly, plasminogen-depleted human fibrinogen (Calbiochem; EMD Biosciences) was incubated at $0.86 \mathrm{mg} / \mathrm{ml}$ with $10 \mathrm{U} / \mathrm{ml}$ of rabbit skeletal muscle peptidyl arginine deiminase (Sigma-Aldrich) in $0.1 \mathrm{M}$ Tris- $\mathrm{HCl}$ ( $\mathrm{pH} 7.4), 10 \mathrm{mM} \mathrm{CaCl}_{2}$, and $5 \mathrm{mM}$ DTT for 2 hours at $50^{\circ} \mathrm{C}$. The enzyme was inactivated by adding $2 \%$ SDS and heating at $100^{\circ} \mathrm{C}$ for 3 minutes. Deiminated fibrinogen was dialyzed against $0.01 \mathrm{M}$ carbonate buffer overnight and biotinylated using NHS-LC biotin (Pierce Biotechnology). Biotinylated, deiminated fibrinogen was used to detect cells producing antibodies against deiminated fibrinogen. In a similar way, biotinylated human IgG (Jackson ImmunoResearch Laboratories Inc.) was used to visualize rheumatoid factor-producing cells. Citrullinated proteins were detected with the anti-modified citrullinated protein kit (Upstate USA Inc.) using published protocols $(68,69)$. Sections that were not chemically modified, sections without primary antibody, and sections from healthy lung were used as controls.

RNA purification and PCR. Total RNA from healthy lungs was obtained from Chemicon International and Cell Applications Inc. RNA was extracted from lung biopsies using the RNeasy Maxi Kit from QIAGEN. Total RNA $(2 \mu \mathrm{g})$ was reverse transcribed using SuperScript II and random hexamers (Invitrogen). cDNA (20 ng) was added to each well of a PCR array for quantitative PCR (Human Inflammatory Cytokines \& Receptors and Human Angiogenesis arrays, RT² Profiler PCR Array; SuperArrays). PCR cycles were performed according to the manufacturer's instructions. The relative level of mRNA expression for each gene in each sample was first normalized to the expression of 18S RNA in that sample and then normalized to the level of mRNA expression in healthy lung.

For semiquantitative PCR, $2 \mu \mathrm{g}$ of RNA from each sample was treated with 2 units of amplification-grade DNAse I (Invitrogen) for 30 minutes at room temperature. DNAse was inactivated by adding $1 \mu \mathrm{l}$ of $25 \mathrm{mM}$ EDTA (Invitrogen) and heating at $65^{\circ} \mathrm{C}$ for 10 minutes. cDNA was generated from $2 \mu \mathrm{g}$ of DNAse-treated RNA using SuperScript II and random hexamers (Invitrogen). cDNA (100 ng) was amplified using Expand High Fidelity PCR System (Roche Diagnostics). Cycling conditions and primers were as follows: $\beta-2$ microglobulin, 35 cycles (70); BAFF, 35 cycles (70); ICOS, 38 cycles (71); ICOS-L, 38 cycles (71); and PADI-2, 38 cycles (72). A total of $25 \mu \mathrm{l}$ of the PCR product was loaded in $1 \%$ agarose gels, resolved for 1 hour, and visualized by ethidium bromide. Images were taken with a Gel Doc 1000 (Bio-Rad) and saved as TIFFs.

\section{Acknowledgments}

This work was supported by NIH grants HL69409 and HL63925, the Sandler Program for Asthma Research, and the Trudeau Institute. The authors would like to thank Frances Lund for her critical evaluation of this manuscript.

Received for publication April 5, 2006, and accepted in revised form October 10, 2006.

Address correspondence to: Troy D. Randall, Trudeau Institute, Saranac Lake, New York 12983, USA. Phone: (518) 891-3080; Fax: (518) 891-5126; E-mail: trandall@trudeauinstitute.org.
1. Sminia, T., van der Brugge-Gamelkoorn, G.J., and Jeurissen, S.H. 1989. Structure and function of bronchus-associated lymphoid tissue (BALT). Crit. Rev. Immunol. 9:119-150.

2. Pabst, R., and Gehrke, I. 1990. Is the bronchusassociated lymphoid tissue (BALT) an integral structure of the lung in normal mammals, including humans? Am. J. Respir. Cell Mol. Biol. 3:131-135.

3. Tschernig, T., and Pabst, R. 2000. Bronchus-associated lymphoid tissue (BALT) is not present in the normal adult lung but in different diseases. Pathobiology. 68:1-8.
4. Moyron-Quiroz, J.E., et al. 2004. Role of inducible bronchus associated lymphoid tissue (iBALT) in respiratory immunity. Nat. Med. 10:927-934.

5. Suda, T., et al. 1999. Development of bronchusassociated lymphoid tissue in chronic hypersensitivity pneumonitis. Chest. 115:357-363. 
6. Brodie, S.J., et al. 1999. Pediatric AIDS-associated lymphocytic interstitial pneumonia and pulmonary arterio-occlusive disease: role of VCAM-1/ VLA-4 adhesion pathway and human herpesviruses. Am. J. Pathol. 154:1453-1464.

7. Hogg, J.C., et al. 2004. The nature of small-airway obstruction in chronic obstructive pulmonary disease. N. Engl. J. Med. 350:2645-2653.

8. Sato, A., Hayakawa, H., Uchiyama, H., and Chida, K. 1996. Cellular distribution of bronchus-associated lymphoid tissue in rheumatoid arthritis. Am. J. Respir. Crit. Care Med. 154:1903-1907.

9. Wallace, W.A.H., Howie, S.A.M., Krajewski, A.S., and Lamb, D. 1996. The immunological architecture of B-lymphocyte aggregates in cryptogenic fibrosing alveolitis. J. Pathol. 178:323-329.

10. Gould, S.J., and Isaacson, P.G. 1993. Bronchusassociated lymphoid tissue (BALT) in human fetal and infant lung. J. Pathol. 169:229-234.

11. Goodnow, C.C. 1997. Chance encounters and organized rendezvous. Immunol. Rev. 156:5-10.

12. Cyster, J.G. 1999. Chemokines and cell migration in secondary lymphoid organs. Science. 286:2098-2102.

13. Muller, G., Hopken, U.E., Stein, H., and Lipp, M. 2002. Systemic immunoregulatory and pathogenic functions of homeostatic chemokine receptors. J. Lenkoc. Biol. 72:1-8.

14. Gunn, M.D., et al. 1998. A B-cell-homing chemokine made in lymphoid follicles activates Burkitt's lymphoma receptor-1. Nature. 391:799-803.

15. Ansel, K.M., et al. 1999. In vivo-activated CD4 T cells upregulate CXC chemokine receptor 5 and reprogram their response to lymphoid chemokines. J. Exp. Med. 190:1123-1134.

16. Luther, S.A., Tang, H.L., Hyman, P.L., Farr, A.G., and Cyster, J.G. 2000. Coexpression of the chemokines ELC and SLC by T zone stromal cells and deletion of the ELC gene in the plt/plt mouse. Proc. Natl. Acad. Sci. U. S. A. 97:12694-12699.

17. Gunn, M.D., et al. 1999. Mice lacking expression of secondary lymphoid organ chemokine have defects in lymphocyte homing and dendritic cell localization. J. Exp. Med. 189:451-460.

18. Luther, S.A., Ansel, K.M., and Cyster, J.G. 2003. Overlapping roles of CXCL13, interleukin 7 receptor alpha, and CCR7 ligands in lymph node development. J. Exp. Med. 197:1191-1198.

19. Cupedo, T., and Mebius, R.E. 2003. Role of chemokines in the development of secondary and tertiary lymphoid tissues. Semin. Immunol. 15:243-248.

20. Nishikawa, S., Honda, K., Vieira, P., and Yoshida, H. 2003. Organogenesis of peripheral lymphoid organs. Immunol. Rev. 195:72-80.

21. Cupedo, T., Kraal, G., and Mebius, R.E. 2002. The role of CD 45+CD4+CD3- cells in lymphoid organ development. Immunol. Rev. 189:41-50.

22. Goya, S., et al. 2003. Sustained interleukin-6 signalling leads to the development of lymphoid organlike structures in the lung. J. Pathol. 200:82-87.

23. Chen, S.C., et al. 2002. Ectopic expression of the murine chemokines CCL21a and CCL21b induces the formation of lymph node-like structures in pancreas, but not skin, of transgenic mice. J. Immunol. 168:1001-1008.

24. Magliozzi, R., Columba-Cabezas, S., Serafini, B., and Aloisi, F. 2004. Intracerebral expression of CXCL13 and BAFF is accompanied by formation of lymphoid follicle-like structures in the meninges of mice with relapsing experimental autoimmune encephalomyelitis. J. Neuroimmunol. 148:11-23.

25. Baddoura, F.K., et al. 2005. Lymphoid neogenesis in murine cardiac allografts undergoing chronic rejection. Am. J. Transplant. 5:510-516.

26. Martin, A.P., et al. 2004. A novel model for lymphocytic infiltration of the thyroid gland generated by transgenic expression of the CC chemokine CCL21. J. Immunol. 173:4791-4798.
27. Xanthou, G., et al. 2001. "Lymphoid" chemokine messenger RNA expression by epithelial cells in the chronic inflammatory lesion of the salivary glands of Sjogren's syndrome patients: possible participation in lymphoid structure formation. Arthritis Rheum. 44:408-418.

28. Amft, N., et al. 2001. Ectopic expression of the B cell-attracting chemokine BCA-1 (CXCL13) on endothelial cells and within lymphoid follicles contributes to the establishment of germinal center-like structures in Sjogren's syndrome. Artbritis Rheum. 44:2633-2641.

29. Salomonsson, S., et al. 2003. Cellular basis of ectopic germinal center formation and autoantibody production in the target organ of patients with Sjogren's syndrome. Arthritis Rheum. 48:3187-3201.

30. Armengol, M.P., et al. 2001. Thyroid autoimmune disease: demonstration of thyroid antigen-specific $B$ cells and recombination-activating gene expression in chemokine-containing active intrathyroidal germinal centers. Am. J. Pathol. 159:861-873.

31. Armengol, M.P., et al. 2003. Chemokines determine local lymphoneogenesis and a reduction of circulating CXCR4+ T and CCR7 B and T lymphocytes in thyroid autoimmune diseases. J. Immunol. 170:6320-6328.

32. Shi, K., et al. 2001. Lymphoid chemokine B cellattracting chemokine-1 (CXCL13) is expressed in germinal center of ectopic lymphoid follicles within the synovium of chronic arthritis patients. J. Immunol. 166:650-655.

33. Takemura, S., et al. 2001. Lymphoid neogenesis in rheumatoid synovitis. J. Immunol. 167:1072-1080.

34. Hjelmstrom, P. 2001. Lymphoid neogenesis: de novo formation of lymphoid tissue in chronic inflammation through expression of homing chemokines. J. Leukoc. Biol. 69:331-339.

35. Manzo, A., et al. 2005. Systematic microanatomical analysis of CXCL13 and CCL21 in situ production and progressive lymphoid organization in rheumatoid synovitis. Eur. J. Immunol. 35:1347-1359.

36. Carlsen, H.S., Baekkevold, E.S., Johansen, F.E., Haraldsen, G., and Brandtzaeg, P. 2002. B cell attracting chemokine 1 (CXCL13) and its receptor CXCR5 are expressed in normal and aberrant gut associated lymphoid tissue. Gut. 51:364-371.

37. Mazzucchelli, L., et al. 1999. BCA-1 is highly expressed in Helicobacter pylori-induced mucosaassociated lymphoid tissue and gastric lymphoma. J. Clin. Invest. 104:R49-R54.

38. Aloisi, F., and Pujol-Borrell, R. 2006. Lymphoid neogenesis in chronic inflammatory diseases. Nat. Rev. Immunol. 6:205-217.

39. Drayton, D.L., Liao, S., Mounzer, R.H., and Ruddle, N.H. 2006. Lymphoid organ development: from ontogeny to neogenesis. Nat. Immunol. 7:344-353.

40. King, T.E., Jr. 2005. Clinical advances in the diagnosis and therapy of the interstitial lung diseases. $A m$. J. Respir. Crit. Care Med. 172:268-279.

41. Selman, M., King, T.E., and Pardo, A. 2001. Idiopathic pulmonary fibrosis: prevailing and evolving hypotheses about its pathogenesis and implications for therapy. Ann. Intern. Med. 134:136-151.

42. Vissers, J.L., Hartgers, F.C., Lindhout, E., Figdor, C.G., and Adema, G.J. 2001. BLC (CXCL13) is expressed by different dendritic cell subsets in vitro and in vivo. Eur. J. Immunol. 31:1544-1549.

43. Hjelmstrom, P., et al. 2000. Lymphoid tissue homing chemokines are expressed in chronic inflammation. Am. J. Pathol. 156:1133-1138.

44. Ansel, K.M., et al. 2000. A chemokine-driven positive feedback loop organizes lymphoid follicles. Nature. 406:309-314.

45. Drayton, D.L., et al. 2004. I kappa B kinase complex alpha kinase activity controls chemokine and high endothelial venule gene expression in lymph nodes and nasal-associated lymphoid tissue. J. Immunol. 173:6161-6168.
46. Ying, X., Chan, K., Shenoy, P., Hill, M., and Ruddle, N.H. 2005. Lymphotoxin plays a crucial role in the development and function of nasal-associated lymphoid tissue through regulation of chemokines and peripheral node addressin. Am. J. Pathol. 166:135-146.

47. Cattoretti, G., et al. 1995. BCL-6 protein is expressed in germinal-center B cells. Blood. 86:45-53.

48. Dent, A.L., Shaffer, A.L., Yu, X., Allman, D., and Staudt, L.M. 1997. Control of inflammation, cytokine expression, and germinal center formation by BCL-6. Science. 276:589-592.

49. Yamada, R., Suzuki, A., Chang, X., and Yamamoto, K. 2005. Citrullinated proteins in rheumatoid arthritis. Front. Biosci. 10:54-64.

50. Bienenstock, J., and Johnston, N. 1976. A morphologic study of rabbit bronchial lymphoid aggregates and lymphoepithelium. Lab. Invest. 35:343-348.

51. Bienenstock, J., and McDermott, M.R. 2005. Bronchus- and nasal-associated lymphoid tissues. Immunol. Rev. 206:22-31.

52. Gregson, R.L., Edmondson, N.A., and Plesch, B. 1982. Preferential uptake of soluble antigen by respiratory tract epithelium overlying bronchusassociated lymphoid tissue in the rat. Adv. Exp. Med. Biol. 149:499-505.

53. Tango, M., Suzuki, E., Gejyo, F., and Ushiki, T. 2000. The presence of specialized epithelial cells on the bronchus-associated lymphoid tissue (BALT) in the mouse. Arch. Histol. Cytol. 63:81-89.

54. Ersch, J., Tschernig, T., and Stallmach, T. 2005. Frequency and potential cause of bronchus-associated lymphoid tissue in fetal lungs. Pediatr. Allergy Immunol. 16:295-298.

55. Escolar Castellon, J.D., Escolar Castellon, A., Roche Roche, P.A., and Minana Amada, C. 1992. Bronchial-associated lymphoid tissue (BALT) response to airway challenge with cigarette smoke, bovine antigen and anti-pulmonary serum. Histol. Histopathol. 7:321-328.

56. Richmond, I., et al. 1993. Bronchus associated lymphoid tissue (BALT) in human lung: its distribution in smokers and non-smokers. Thorax. 48:1130-1134.

57. Weninger, W., et al. 2003. Naive T cell recruitment to nonlymphoid tissues: a role for endotheliumexpressed CC chemokine ligand 21 in autoimmune disease and lymphoid neogenesis. J. Immunol. 170:4638-4648.

58. Luther, S.A., Lopez, T., Bai, W., Hanahan, D., and Cyster, J.G. 2000. BLC expression in pancreatic islets causes B cell recruitment and lymphotoxin-dependent lymphoid neogenesis. Immunity. 12:471-481.

59. Endres, R., et al. 1999. Mature follicular dendritic cell networks depend on expression of lymphotoxin $b$ receptor by radioresistant stromal cells and of lymphotoxin b and tumor necrosis factor by $\mathrm{B}$ cells. J. Exp. Med. 189:159-167.

60. Rangel-Moreno, J., et al. 2005. Role of CXC chemokine ligand $13, \mathrm{CC}$ chemokine ligand (CCL) 19 , and CCL2 1 in the organization and function of nasal-associated lymphoid tissue. J. Immunol. 175:4904-4913.

61. Wills-Karp, M. 2004. Interleukin-13 in asthma pathogenesis. Immunol. Rev. 202:175-190.

62. American Thoracic Society. 2002. American Thoracic Society/European Respiratory Society International Multidisciplinary Consensus Classification of the Idiopathic Interstitial Pneumonias. This joint statement of the American Thoracic Society (ATS), and the European Respiratory Society (ERS) was adopted by the ATS board of directors, June 2001 and by the ERS Executive Committee, June 2001. Am. J. Respir. Crit. Care Med. 165:277-304.

63. Pardo, A., et al. 2000. Increase of lung neutrophils in hypersensitivity pneumonitis is associated with lung fibrosis. Am. J. Respir. Crit. Care Med. 161:1698-1704. 
64. Arnett, F.C., et al. 1988. The American Rheumatism Association 1987 revised criteria for the classification of rheumatoid arthritis. Arthritis Rheum. 31:315-324.

65. Vitali, C., et al. 1993. Preliminary criteria for the classification of Sjogren's syndrome. Results of a prospective concerted action supported by the European Community. Arthritis Rheum. 36:340-347.

66. Lee, H.K., et al. 2005. Histopathologic pattern and clinical features of rheumatoid arthritis-associated interstitial lung disease. Chest. 127:2019-2027.

67. Masson-Bessiere, C., et al. 2001. The major syno- vial targets of the rheumatoid arthritis-specific antifilaggrin autoantibodies are deiminated forms of the alpha- and beta-chains of fibrin. J. Immunol. 166:4177-4184.

68. Makrygiannakis, D., et al. 2006. Citrullination is an inflammation-dependent process. Ann. Rheum. Dis. 65:1219-1222.

69. Ishigami, A., et al. 2005. Abnormal accumulation of citrullinated proteins catalyzed by peptidylarginine deiminase in hippocampal extracts from patients with Alzheimer's disease. J. Neurosci. Res. 80:120-128.
70. Kern, C., et al. 2004. Involvement of BAFF and APRIL in the resistance to apoptosis of B-CLL through an autocrine pathway. Blood. 103:679-688.

71. Schmidt, J., Rakocevic, G., Raju, R., and Dalakas, M.C. 2004. Upregulated inducible co-stimulator (ICOS) and ICOS-ligand in inclusion body myositis muscle: significance for CD8+ T cell cytotoxicity. Brain. 127:1182-1190.

72. Nachat, R., et al. 2005. Peptidylarginine deiminase isoforms 1-3 are expressed in the epidermis and involved in the deimination of $\mathrm{K} 1$ and filaggrin. J. Invest. Dermatol. 124:384-393. 